\title{
A Study on Analysing Speaking-pen Learning Log Data Considering Interests for Improvement of Primary School Children's English Ability
}

\author{
Wataru Ogawara, Michiko Tsubaki and Naoto Nagamori \\ The University of Electro-Communications \\ Tokyo, Japan
}

\begin{abstract}
As globalization advances, early English education for children in non-English speaking countries has been regarded as important. Many studies have proposed effective learning methods; however, few of these have analysed the relationship between learning processes and their effects with respect to detailed, classified interests. This study investigated and proposed detailed learners' interests in primary school children's English learning as variables from log data obtained through learning with a speaking-pen, and analysed the relationship between features of learners' interests and their improvements. Children were classified into four types based on their initial abilities, and an effective learning method was hypothesized for each type. The relationship between the features of children's interests and variables related to self-regulated learning and English education, and their improvement of English skills, were then analysed. As a result, the validity of using variables of interests for understanding factors in English skill improvement was shown.
\end{abstract}

Keywords: Classification; Interest in learning; Learning process data; Regression tree.

\section{Introduction}

As globalization proceeds, various educational reforms for improving English ability have been practiced in numerous non-English speaking countries. Actual English education policies in the Asia-Pacific region and their practical problems were detailed by Nunan (2003). In Japan, the curriculum guidelines for elementary schools were revised and English language activities were established for children of grades 5 and 6 by the Ministry of Education, Culture, Sports, Science and Technology (2011). Moreover, the Ministry of Education, Culture, Sports, Science and Technology announced the 'English Education Reform Plan Corresponding to Globalization' in 2013, and in 2014 presented five proposals through the advisory council on the management of English education. These five proposals are detailed, concrete guidelines concerning educational 
goals and improvement of content, improvement of instruction and evaluation in school, evaluation of English ability among high school and university students and the improvement of the university entrance exam, enrichment of teaching materials, and comprehensiveness of the school instruction system (Ministry of Education, Culture, Sports, Science and Technology, 2014).

In light of this historical context, research in early English education is vital. Liu and Chu (2010) showed improvement in both learning outcomes and motivation in grade 7 students with an English education technique that used ubiquitous games as learning material. Tsubaki, Gonda, Kato, and Maeda (2015) proposed 30 variables for English education and self-regulated learning in primary school children's English learning, and modelled the four basic English skills for improvement to verify the effectiveness of each learning strategy, after classifying children into four types based on the results of a pre-test. Mavilidi et al. (2015) examines effects of human movement on learning foreign languages in preschool children and shows the superiority of using physical exercises to enact words in learning foreign words.

On the other hand, the effect of learners' interests on study and cognition has been examined and verified extensively. Hidi (1990) showed that interests are central elements in determining how people select and maintain certain types of information processing in preference to others. As a case study, Renninger, Ewen, and Lasher (2002) discussed the interests of 11-year-old children. Tools that can improve learner skill and teacher support are required for children who have low skills but high interest, and advice on deep understanding of content is needed for children with high skill but low interest (Renninger, Ewen, and Lasher, 2002). Highly interested readers cannot represent the surface but propositional explanation (Schiefele, 1996), then high interest is considered to relate to qualitative development independent of current knowledge or language skills. Furthermore, Ainley, Hidi, and Berndorff (2002) studied the process by which personal and situational interests contribute to learning. Ainley and Ainley (2011) verified the contribution of enjoyment to interest in science learning among students in four different countries.

Tanaka (2015) proposed a detailed classification of interests in science for children from elementary grade 5 to high school grade 1, and analysed the relationship between the characteristics of each interest to development of meaningful understanding strategies and learning activities. Although the features of the classified interests were examined, however, the factors of such interests that improve learning were not analysed in detail.

The present study examines and proposes variables concerning interest in primary school children's English learning, based on the classification of interest in science learning created by Tanaka (2015); it then analyses the relationship between these interests' features in the English learning process of elementary school children and their English ability improvement. Improving upon previous variables for self-regulated learning and English education, proposed by Tsubaki et al. (2015), the study analyses effective learning elements in terms 
of interest, self-regulated learning and English education variables; the interest variables are evaluated by comparing them with the analysis results.

First, the investigation summary, experimental design and learning materials are explained. Next, interest variables for the English learning of primary school children are examined and proposed based on the classification of interests in science by Tanaka (2015). Variables previously proposed by Tsubaki et al. (2015) are also improved upon and used in this research. Children are classified into types based on their initial English skill, and hypothesized effective learning methods are proposed for each type. Finally, the features of children who showed improvement are analysed by regression trees to verify the hypotheses.

\section{Overview of the research}

\section{Investigation}

This research analyses learning process data obtained from a Speaking-pen learning trial involving 90 students (parental consent was obtained for all participating children) from grade 2 of the private Shukutoku Elementary School in Japan. Since this school has its own curriculum that allows children to study English beginning in grade 1, its students' English skills are considered to be more highly developed than those of ordinary elementary students. Initially, the children and their parents completed individual questionnaires to provide an understanding of the children's background, such as English learning environment, motivation and experience. Based on the answers, eight dependent categories were established by combining experience using a Speaking-pen, experience studying English, and home learning practices; for each category, children were allocated to one of two groups using a Bernoulli trial with the parameter set to 0.5 (see Figure. 1).

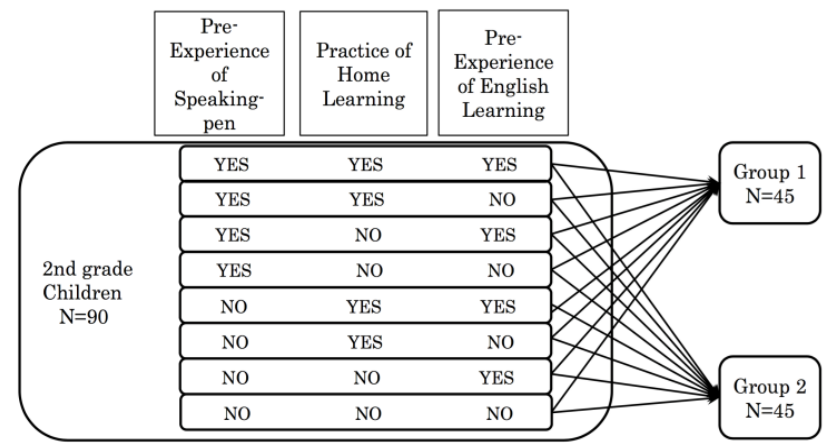

Figure 1: Grouping allocation.

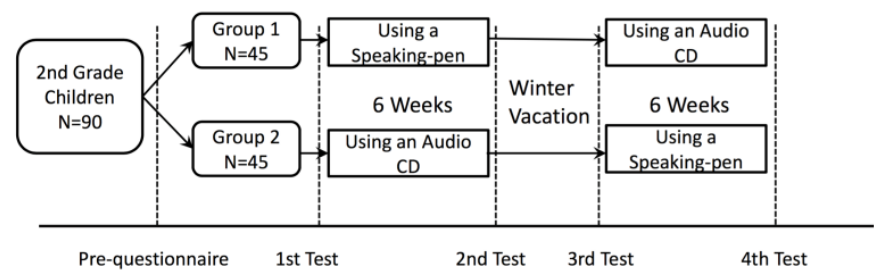

Figure 2: Experiment design using the crossover method. 
As shown in Figure. 2, one group studied at home with the Speaking-pen for the first six weeks and with a CD for the second six weeks after winter vacation, while the other group studied with a CD for the first six weeks and with a Speaking-pen for the second six weeks after vacation. This experiment did not enforce their study (e.g., study amount or timing), and all participants were directed to respect the intention of the children. To analyse effectiveness, a crossover study was used, measuring two test scores on the baseline and the second point of each term (see Fig. 2). In the experiment, each of the children used a Speaking-pen and the textbook developed for use with the Speaking-pen.

A usual Speaking-pen is a learning material which provides learners the opportunity of listening. When learners push the dots embedded in the words or sentences on a textbook, the Speaking-pen pronounces them. Then, learners using a Speaking-pen can focus on learning of listening about the content which they want to learn, unlike the learners using an audio CD have to listen to the English in order of a textbook. Furthermore, the Speaking-pen used in this study not only plays the words and conversations in the textbook, but also enables learners to record and replay their own pronunciations. Moreover, because the Speaking-pen links to dots embedded in each question, information about the learning process can be obtained via log data, such as the order in which questions are solved and their results. The Speaking-pen is made by Gridmark, Inc.

\section{Textbook}

The textbook consists of four units, each with seven parts. The children studied two units during each six-week period before and after the winter vacation (see Figure. 2).

In Part 1, the children practice some basic thematic conversations of the unit, such as 'What do you like?' / 'I like cake', using the Speaking-pen for reading, listening and speaking. Therefore, the children can improve their reading, speaking and listening ability in this part. In Part 2, the children read the words below the pictures, such as 'cake', then listen to and speak the words using the Speaking-pen. Therefore, the children can improve their reading, speaking and listening ability in this part. In Part 3, the children can listen to questions such as 'What do you like?' using the Speaking-pen, then read five words and select the appropriate answer based on the pictures in the textbook (see Figure. 5). This enables them to learn the expression of and responses to the questions. Therefore, the children can improve their reading and listening ability in this part. In Part 4, the children can use the Speaking-pen to hear pronunciations of the words in the textbook, then indicate their spelling using a picture of letters (see Figure. 6). This writing practice removes the process of actual writing, so it is considered easier for children even when they lack motivation. Therefore, the children can improve their listening and writing ability in this part. In Part 5, the children can read and write words beside the corresponding picture in the textbook. Moreover, the Speaking-pen enables the children to hear the pronunciation of each word. Therefore, the children can improve their reading, listening and writing ability in this part. In Part 6, the children can listen to questions, the 
main theme of the part, and select the answer that best matches the picture shown (see Figure. 8). Therefore, the children can improve their listening and reading ability in this part. In Part 7, the children can listen to the pronunciation of words using the Speaking-pen and correct their own pronunciation by recording and playing back their speech. In addition, spaces for writing the words are provided, as in part 5, so they can also practice writing. Therefore, the children can improve their listening, reading, writing and speaking ability in this part.

We examined which parts of the textbook address which skills, and the relationships are shown in Table 1.

Table1: English Learning Skills Related to Each Part of the Textbook

\begin{tabular}{cl}
\hline \hline Section & \multicolumn{1}{c}{ English learning skills } \\
\hline Part 1 & Listening, reading and speaking \\
Part 2 & Listening, reading and speaking \\
Part 3 & Listening and reading \\
Part 4 & Listening and writing \\
Part 5 & Listening, reading and writing \\
Part 6 & Listening and reading \\
Part 7 & All \\
\hline \hline
\end{tabular}

Test

Each test is organized into six parts similar to the textbook.

In Part 1, the children are required to read words and link them to the appropriate pictures. One point is allocated to each question for a total of 15 . In Part 2, the children are required to fill in a blank with the appropriate letter to complete each word according to the matching picture. Two points are allocated to each question for a total of 20. In Part 3, the children are required to read question sentences and select the appropriate answer by referring to the matching pictures. This part is considered to be difficult for the children because they have to understand the meaning of questions, unlike in part 2. Two points are allocated to each question for a total of 10. In Part 4, the children are required to listen to questions and select the appropriate answer by referring to the matching pictures. Four points are allocated to each question for a total of 20. In Part 5, the children are required to listen to sentences and fill in a blank with the appropriate letter to complete a word. Four points are allocated to each question for a total of 20. In Part 6, the children are required to respond to three questions asked by a native English speaking teacher, such as 'What's your name?', 'What's this?' and 'How old are you?' Five points are allocated to each question for a total of 15. 
The English skills measured in each part of the test are shown in Table 2.

Table2: English Skills Measured by the Test

\begin{tabular}{cl}
\hline \hline Section & \multicolumn{1}{c}{ English skills measured } \\
\hline Part 1 & Reading \\
Part 2 & Writing \\
Part 3 & Reading \\
Part 4 & Listening \\
Part 5 & Listening and Writing \\
Part 6 & Listening and Speaking \\
\hline \hline
\end{tabular}

\section{Proposal and investigation of variables of interest in learning English}

Tanaka (2015) proposes and examines six types of interest in science. Interest based on experience of experiments, interest based on surprise and discovery, and interest based on achievement are classified as shallow interests, while interest based on acquiring knowledge, interest based on vitalizing thinking, and interest related to daily life are classified as deep interests. According to Tanaka (2015), the need for knowledge is low for interest based on experience of experiments and interest based on surprise and discovery, and medium for interest based on achievement and interest based on acquiring knowledge. On the contrary, the need for knowledge is high for interest based on vitalizing thinking, and highest for interest related to daily life. In addition, Tanaka (2015) remarks that interest based on vitalizing thinking and interest related to daily life are potentially important factors in science learning, because students who demonstrate high levels of such interest tend to study positively using learning strategies effective in understanding meaning.

This research proposes and investigates children's interest in learning English using learning process data, to which the science learning interests of Tanaka (2015) are expanded. In Table 3 to 9, S expresses Success in a question, F expresses Failure in a question and $\mathrm{O}$ expresses other log.

\section{Interest related to daily life}

The emergence of interest related to daily life was defined as the case in which children study words or sentences related to their daily lives. This study makes a distinction between the terms 'related to daily life' and 'familiar'. For example, animals seen only in a zoo or a picture book are considered not to be related to daily life, even if they are familiar.

Table 3: Learning Process Log Data Representing Interest Related to Daily Life

\begin{tabular}{ccccc}
\hline \hline Date & Time & Part & Content & Log \\
\hline 10.28 & $16: 42: 01$ & 2 & red & O \\
10.28 & $16: 42: 08$ & 2 & red & O \\
10.28 & $16: 42: 35$ & 2 & yellow & O \\
10.28 & $16: 43: 25$ & 2 & green & O \\
10.28 & $16: 43: 53$ & 2 & orange & O \\
10.28 & $16: 44: 08$ & 2 & purple & O \\
10.28 & $16: 44: 21$ & 2 & blue & O \\
\hline \hline
\end{tabular}


As shown in Table 3, a child was judged to have interest related to daily life in the case where the child studied the words 'red' or 'yellow', which are seen in daily life.

\section{Interest based on vitalizing thinking}

The emergence of interest based on vitalizing thinking was defined as the case in which a child studied in one of the following ways: learning content related to sentence structure, learning all content about a story in sequence, solving questions without incorrect answers, and solving difficult questions correctly.

Table 4: Learning Process Log Data Representing Interest Based on Vitalizing Thinking (Learning All Story Content in Sequence)

\begin{tabular}{ccccc}
\hline \hline Date & Time & Part & Content & Log \\
\hline 10.28 & $16: 33: 41$ & 1 & $1-1$ & O \\
10.28 & $16: 33: 45$ & 1 & $1-1$ & O \\
10.28 & $16: 33: 48$ & 1 & $1-2$ & O \\
10.28 & $16: 33: 51$ & 1 & $2-1$ & O \\
10.28 & $16: 33: 54$ & 1 & $2-2$ & O \\
10.28 & $16: 33: 57$ & 1 & $3-1$ & O \\
10.28 & $16: 34: 00$ & 1 & $3-2$ & O \\
10.28 & $16: 34: 03$ & 1 & $4-1$ & O \\
10.28 & $16: 34: 06$ & 1 & $4-2$ & O \\
10.28 & $16: 34: 11$ & 1 & $4-2$ & O \\
10.28 & $16: 34: 23$ & 1 & $1-1$ & O \\
\hline \hline
\end{tabular}

As shown in Table 4, a child was judged to have interest based on vitalizing thinking in the case where the child practiced all the content about the story in sequence.

\section{Interest based on acquiring knowledge}

The emergence of interest based on acquiring knowledge was defined as the case in which a child studied in one of the following ways: learning the same content repeatedly, learning difficult questions with words not related to daily life, and learning all items from one part.

Table 5: Learning Process Log Data Representing Interest Based on Acquiring Knowledge (Learning the Same Content Repeatedly)

\begin{tabular}{ccccc}
\hline \hline Date & Time & Part & Content & Log \\
\hline 10.28 & $18: 04: 10$ & 2 & whale & O \\
10.28 & $18: 04: 11$ & 2 & giraffe & O \\
10.28 & $18: 04: 11$ & 2 & (Record) & O \\
10.28 & $18: 04: 12$ & 2 & giraffe & O \\
10.28 & $18: 04: 20$ & 2 & (Record) & O \\
10.28 & $18: 04: 24$ & 2 & giraffe & O \\
10.28 & $18: 04: 30$ & 2 & giraffe & O \\
10.28 & $18: 04: 36$ & 2 & (Record) & O \\
10.28 & $18: 04: 40$ & 2 & giraffe & O \\
10.28 & $18: 04: 46$ & 2 & giraffe & O \\
\hline \hline
\end{tabular}


As shown in Table 5, a child was judged to have interest based on acquiring knowledge in the case where the child practiced the words 'giraffe' and 'leopard' repeatedly.

\section{Interest based on achievement}

The emergence of interest based on achievement was defined as the case in which a child studied in one of the following ways: learning words or sentence structures by skipping through more than two parts, continuing to solve questions with wrong answers until the correct answer was obtained, and studying questions repeatedly after the correct answer was obtained.

Table 6: Learning Process Log Data Representing Interest Based on Achievement (Learning Questions Repeatedly after the Correct Answer Was Obtained)

\begin{tabular}{ccccc}
\hline Date & Time & Part & Content & Log \\
\hline 10.28 & $19: 17: 30$ & 3 & Q4 & Q \\
10.28 & $19: 17: 32$ & 3 & $4-2$ & S \\
10.28 & $19: 17: 34$ & 3 & Q5 & Q \\
10.28 & $19: 17: 36$ & 3 & $5-5$ & S \\
10.28 & $19: 17: 38$ & 3 & $5-1$ & O \\
10.28 & $19: 17: 40$ & 3 & $5-2$ & O \\
10.28 & $19: 17: 41$ & 3 & $5-3$ & O \\
10.28 & $19: 17: 43$ & 3 & $5-3$ & O \\
10.28 & $19: 17: 44$ & 3 & $5-4$ & O \\
10.28 & $19: 17: 45$ & 3 & $5-5$ & O \\
10.28 & $19: 17: 47$ & 3 & $5-1$ & O \\
\hline \hline
\end{tabular}

As shown in Table 6, a child was judged to have interest based on achievement in the case where the child learned questions repeatedly after the correct answer 5-5 for Q5 was obtained.

\section{Interest based on familiarity}

The emergence of interest based on familiarity was defined as the case in which a child learns words that, while not related to daily life, are still familiar.

Table 7: Learning Process Log Data Representing Interest Based on Familiarity (Learning Familiar Words)

\begin{tabular}{lllll}
\hline \hline Date & Time & Part & Content & Log \\
\hline 11.16 & $11: 58: 38$ & 4 & panda & $\mathrm{O}$ \\
11.16 & $11: 58: 41$ & 4 & piano & $\mathrm{O}$ \\
11.16 & $11: 58: 44$ & 4 & queen & $\mathrm{O}$ \\
11.16 & $11: 58: 48$ & 4 & Question & $\mathrm{Q}$ \\
11.16 & $11: 59: 05$ & 4 & panda & $\mathrm{O}$ \\
11.16 & $11: 59: 07$ & 4 & piano & $\mathrm{O}$ \\
11.16 & $11: 59: 09$ & 4 & queen & $\mathrm{O}$ \\
\hline \hline
\end{tabular}

As shown in Table 7, a child was judged to have interest based on familiarity in the case where the child learned words like 'panda' or 'queen', which are not related to daily life, but are familiar. 


\section{Interest based on surprise and discovery}

The emergence of interest based on surprise and discovery was defined as the case in which a child studied words related to daily life that surprise the child or are found difficult to pronounce or use.

Table 8: Learning Process Log Data Representing Interest Based on Surprise and Discovery (Learning Popular Words That Are Difficult to Pronounce)

\begin{tabular}{ccccc}
\hline \hline Date & Time & Part & Content & Log \\
\hline 10.28 & $19: 05: 31$ & 2 & whale & O \\
10.28 & $19: 06: 04$ & 2 & penguin & O \\
10.28 & $19: 06: 14$ & 2 & whale & O \\
10.28 & $19: 06: 21$ & 2 & whale & O \\
10.28 & $19: 06: 37$ & 2 & whale & O \\
10.28 & $19: 06: 43$ & 2 & whale & O \\
10.28 & $19: 07: 00$ & 2 & whale & O \\
10.28 & $19: 07: 37$ & 2 & leopard & O \\
10.28 & $19: 07: 44$ & 2 & leopard & O \\
10.28 & $19: 07: 59$ & 2 & polar bear & O \\
10.28 & $19: 08: 02$ & 2 & penguin & O \\
\hline \hline
\end{tabular}

As shown in Table 8, a child was judged to have interest based on surprise and discovery in the case where the child practiced words like 'whale' or 'leopard': the names of well-known animals, but with pronunciations or spellings unfamiliar to Japanese children.

\section{Interest based on experience}

Because there are four main English skills, this interest area involves four types of interest based on experience with listening, reading, writing and speaking. The emergence of interest based on reading experience was defined as the case in which a child studied content by skipping through more than two parts. A child was judged to have interest based on reading experience in the case where the child studied content related to reading in one part, then studied reading content in other parts before reaching completing the previous part. Tanaka (2015) defines interest based on the experience of experiments in science as interest based on using or touching experimental materials. Thus, this study defined interest based on experience as the case in which a child studied readings rather than observing the chronological order of parts in the textbook.

Table 9: Learning Process Log Data Representing Interest Based on Reading Experience (Skipping to Reading)

\begin{tabular}{ccccc}
\hline Date & Time & Part & Content & Log \\
\hline 10.28 & $15: 40: 30$ & 1 & $2-1$ & $\mathrm{O}$ \\
10.28 & $15: 40: 34$ & 1 & $2-2$ & $\mathrm{O}$ \\
10.28 & $15: 40: 43$ & 1 & $3-1$ & $\mathrm{O}$ \\
10.28 & $15: 41: 08$ & 2 & orange & $\mathrm{O}$ \\
\hline \hline
\end{tabular}

A child was judged to have interest based on reading experience in the case where the child studied conversations including a reading component, then moved on to other reading portions. 
The definitive variables of interest are shown in Table 10.

\section{Re-examination of self-regulated learning and English education variables}

In previous research, variables of self-regulated learning and English education were proposed as factors affecting study of English (Tsubaki et al., 2015). Self-regulated learning is a method in which the learner regulates his or her own learning based on an achievement target. The effectiveness of self-regulated learning has been proved by numerous studies (e.g., Zimmerman and Martinez-Pons, 1986, Pintrich and De Groot, 1990). The elements of self-regulated learning are 'motivation', 'learning strategy' and 'metacognition' (Zimmerman, 1986, 1989). In this paper, the definition of 'metacognition' is based on Flavell (1976) and Brown and Campione (1981). The variables for English education quantized the learning strategies for English study (e.g., amount of study) as observed for each of the four English abilities.

This research re-examined the level and validity of these variables based on the CEFR-J. The improved variables are listed in Tables 11 and 12.

First, the variables were re-examined based on the CEFR-J. The Common European Framework of Reference for Languages (CEFR) was published by the Council of Europe (2001) to provide a basis for language education for English language learners in Europe. CEFR-J, then, is a reconstructed guideline that extends the CEFR to English learning in Japan (Tono, 2012).

Based on the CEFR-J, the definitions of the two self-regulated learning variables-'Starting with difficult content' and 'Recognition of main point' - were re-examined. For 'Starting with difficult content', Tsubaki et al. (2015) defined 'difficult content' as the end of each part. According to the level suggested by the CEFR-J, however, the difference in difficulty among content in a single part are smaller than those among the content of different units. Thus, the difficulty of each part was examined based on the CEFR-J, and 'difficult content' was defined as parts 3, 4 and 6 in each unit. For 'Recognition of main point', Tsubaki et al. (2015) defined the 'main point' as parts 6 and 7. According to the level suggested by the CEFR-J, however, part 1 - which provides children with an opportunity to practice the theme of the unit in a described conversation-is recognized to be the core part of a unit, with parts 3 and 6 being subordinate, allowing children to study questions and responses based on the theme of the unit. This study thus defined 'main point' as parts 1, 3 and 6 .

Second, the validity of variable level was re-examined. For 'Quantitatively dispersed learning', Tsubaki et al. (2015) assigned level 6 to children who scored an evaluation value of under 0.6. Further investigation of the number of samples in each level showed that a large proportion of the whole were under 0.6. Therefore, another detailed level was added, as shown in Table 11, to characterize the children in detail. 
Table 10: Classification of English Learning Interests

\begin{tabular}{|c|c|c|c|}
\hline & Type & Variable & Definition \\
\hline \multirow[t]{10}{*}{$\begin{array}{c}\text { Value } \\
\text { interests }\end{array}$} & $\begin{array}{l}\text { Related to } \\
\text { daily life }\end{array}$ & $\begin{array}{l}\text { DAILY1 } \\
\text { DAILY2 }\end{array}$ & $\begin{array}{l}\text { Learning words related to daily life } \\
\text { Learning sentences related to daily } \\
\text { life }\end{array}$ \\
\hline & $\begin{array}{l}\text { Vitalizing } \\
\text { thinking }\end{array}$ & THINK1 & $\begin{array}{l}\text { Learning content related to sentence } \\
\text { structure }\end{array}$ \\
\hline & & THINK2 & $\begin{array}{l}\text { Learning all content about a story in } \\
\text { sequence }\end{array}$ \\
\hline & & THINK3 & $\begin{array}{l}\text { Solving questions without incorrect } \\
\text { answers }\end{array}$ \\
\hline & & THINK4 & Solving difficult questions correctly \\
\hline & & TH5AC1 ${ }^{\text {a }}$ & $\begin{array}{l}\text { Learning words by skipping } \\
\text { through more than two parts }\end{array}$ \\
\hline & & TH6AC2 ${ }^{b}$ & $\begin{array}{l}\text { Learning sentences by skipping } \\
\text { through more than two parts }\end{array}$ \\
\hline & $\begin{array}{l}\text { Acquiring } \\
\text { knowledge }\end{array}$ & KNOW1 & $\begin{array}{l}\text { Learning the same content } \\
\text { repeatedly }\end{array}$ \\
\hline & & KNOW2 & $\begin{array}{l}\text { Learning difficult questions with } \\
\text { words not related to daily life }\end{array}$ \\
\hline & & KNOW3 & Learning all items in one part \\
\hline \multirow[t]{10}{*}{$\begin{array}{l}\text { Emotional } \\
\text { interests }\end{array}$} & Achievement & TH5AC1a & $\begin{array}{l}\text { Learning words by skipping } \\
\text { through more than two parts }\end{array}$ \\
\hline & & $\mathrm{TH} \mathrm{AC} 2^{\mathrm{b}}$ & $\begin{array}{l}\text { Learning sentences by skipping } \\
\text { through more than two parts }\end{array}$ \\
\hline & & ACHIEVE3 & $\begin{array}{l}\text { Continuing to solve questions with } \\
\text { wrong answers until the correct } \\
\text { answer is obtained }\end{array}$ \\
\hline & & ACHIEVE4 & $\begin{array}{l}\text { Learning questions repeatedly after } \\
\text { the correct answer was obtained }\end{array}$ \\
\hline & Familiarity & FAMILIAR & $\begin{array}{l}\text { Learning familiar words not related } \\
\text { to daily life }\end{array}$ \\
\hline & $\begin{array}{l}\text { Surprise and } \\
\text { discovery }\end{array}$ & SURPRISE & $\begin{array}{l}\text { Learning words related to daily life } \\
\text { that are surprising and/or difficult } \\
\text { to pronounce or use }\end{array}$ \\
\hline & Experience & LISTEN & $\begin{array}{l}\text { Studying listening content by } \\
\text { skipping through more than two } \\
\text { parts }\end{array}$ \\
\hline & & READ & $\begin{array}{l}\text { Studying reading content by } \\
\text { skipping through more than two } \\
\text { parts }\end{array}$ \\
\hline & & WRITE & $\begin{array}{l}\text { Studying writing content by } \\
\text { skipping through more than two } \\
\text { parts }\end{array}$ \\
\hline & & SPEAK & $\begin{array}{l}\text { Studying speaking content by } \\
\text { skipping through more than two } \\
\text { parts }\end{array}$ \\
\hline
\end{tabular}

aTH5AC1=THINK5=ACHIEVE1, bTH6AC2=THINK6=ACHIEVE2 
Table 11: Self-regulated Learning Interests

\begin{tabular}{|c|c|c|}
\hline Category & Variable & Definition and Levels \\
\hline \multirow[t]{7}{*}{ Motivation } & External regulation & Use of cram school or private teacher \\
\hline & $(\mathrm{EXR})$ & 0: No 1: Once a week 2: Twice a week \\
\hline & $\begin{array}{l}\text { Preference for English } \\
\text { (PRE) }\end{array}$ & 1: Not at all 2: No 3: So-so 4: Yes $\quad$ 5: Extremely \\
\hline & Learning purpose (LPU) & 2: Concrete \\
\hline & $\begin{array}{l}\text { Desire for } \\
\text { communication with } \\
\text { foreigners (DCF) }\end{array}$ & 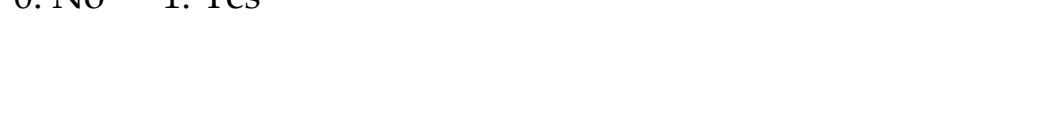 \\
\hline & Utility of learning & Experience using a Speaking-pen \\
\hline & materials (ULM) & 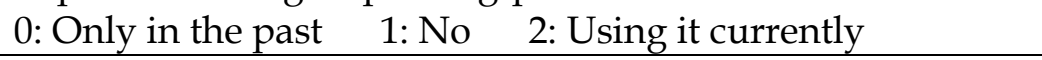 \\
\hline Learning & Vital strategy (VIS) & Abnormal interval between consecutive log data \\
\hline \multirow[t]{19}{*}{ Strategy } & & 0: No 1: Yes \\
\hline & Starting with difficult & Starting with content in parts 3,4 or 6 \\
\hline & content (SDC) & $0:$ No $\quad 1:$ Yes \\
\hline & Starting with easy & Starting with content in parts 1 or 2 \\
\hline & content (SEC) & $0:$ No 1: Yes \\
\hline & Starting with favourite & Starting with content in other parts \\
\hline & content (SFC) & $0:$ No $\quad 1:$ Yes \\
\hline & $\begin{array}{l}\text { Quantitatively dispersed } \\
\text { learning (QDL) }\end{array}$ & $\begin{array}{l}\text { Evaluation level (Count of Speaking-pen uses on the highest } \\
\text { usage day / Cumulative counts of Speaking-pen use } \\
\text { throughout the experiment) }\end{array}$ \\
\hline & & \multirow{2}{*}{ 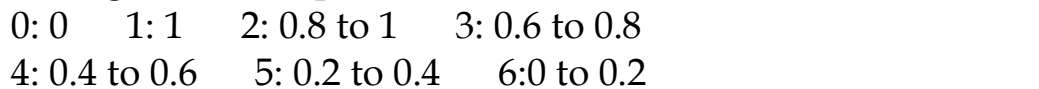 } \\
\hline & & \\
\hline & Constant study (COS) & Weeks of consecutive study \\
\hline & & 0: 0 weeks $\quad 1: 1$ week $2: 2$ weeks $3: 3$ weeks \\
\hline & & 4: 4 weeks $\quad 5: 5$ weeks $\quad 6: 6$ weeks \\
\hline & Interval of study (IOS) & Interval between two learning sessions \\
\hline & & 0: 0 days $\quad 1$ : Over 10 days $\quad 2: 7$ to 9 days \\
\hline & & $4: 1$ to 3 days \\
\hline & Study days (DAY) & Total days of study \\
\hline & & \multirow{2}{*}{$\begin{array}{lll}\text { 0: No study } & 1: 1 \text { to } 2 \text { days } & 2: 3 \text { to } 4 \text { days } \\
\text { 3: } 5 \text { to } 6 \text { days } & 4: 7 \text { to } 8 \text { davs } & 5: 9 \text { or more davs }\end{array}$} \\
\hline & & \\
\hline Metacogniti & Metacognition by & Experience of study with friends \\
\hline & friendship (MFR) & $0:$ No $1:$ Yes \\
\hline & Review (REV) & 0: No 1: On about half the parts $\quad 2$ : On all the parts \\
\hline & Metacognition by & Recognition of parents' contribution in English learning \\
\hline & $\begin{array}{l}\text { parents' contribution } \\
(\mathrm{MPC})\end{array}$ & $0:$ No $1:$ Yes \\
\hline & Recognition of main & Practice in parts 1,3 and 6 \\
\hline & point (REM) & 0: No 1: In part 1 and either 3 or 6 \\
\hline & $\begin{array}{l}\text { Associated with } \\
\text { previous learning (APL) }\end{array}$ & $\begin{array}{l}\text { For A: Used a cram school or private teacher, and B: Marked } \\
\text { over } 60 \% \text { on part } 1 \text { of the first test }\end{array}$ \\
\hline & & 0: Only A $\quad 1:$ Neither A nor B \\
\hline & & 2: Both A and B 3: Only B \\
\hline
\end{tabular}


Table 12: English Education Variables

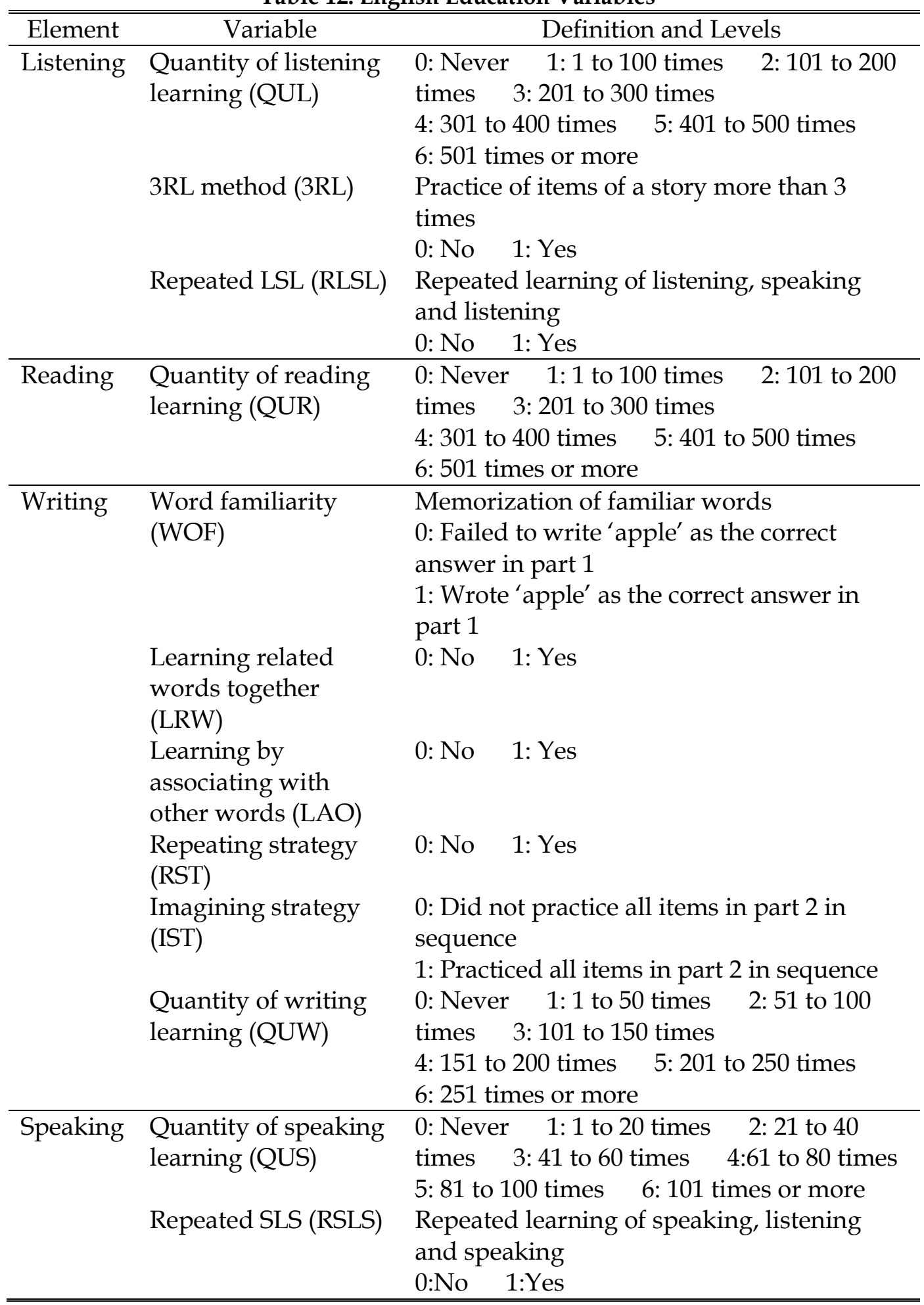

For 'Associated with previous learning', Tsubaki et al. (2015) assigned three levels to evaluate the currentness of students' previous study with a cram school or private teacher using the results of a questionnaire and the correct answer rate for part 1 of the first test. Because this variable aimed to measure the relationship between the children's previous learning environments and their 
current abilities, a better definition of levels was proposed: four levels based on a yes or no response to experience with cram schools or private teachers, and an achievement level of over or under $60 \%$ on part 1 of the first test. For 'Quantity of reading learning', Tsubaki et al. (2015) assigned levels for each interval of 100, with one level for children who scored over 301. Realizing the large variance of quantity of reading learning among the children, however, the levels were reset in order to characterize the children in detailed as shown in Table 12. For 'Quantity of listening learning', the levels were reset using the same process. For the 'Quantity of writing learning', Tsubaki et al. (2015) assigned levels to each interval of 50, with one level for children who scored over 151. Given the large variance of writing learning quantity among the children, the levels were reset in order to characterize the children in detail as shown in Table 12.

Levels for the following two variables were also changed. For 'Imagining Strategy', a method that aims to imagine the actual objects referred to by words, Tsubaki et al. (2015) assigned practice counts of part 2 as the evaluation level. In this research, stricter levels were defined to clarify the essence of the strategy, as shown in Table 11. For 'Repeating strategy', Tsubaki et al. (2015) identified the following three cases as levels: 'No repeating', 'Repeating in part' and 'Repeating the whole text'. In this research, only two levels for 'No repeating' and 'Repeating' were set, as shown in Table 11, to clarify the difference between the 'Repeating' strategy and the 'Reviewing' strategy.

\section{Analysis of English learning process}

\section{Type classification based on initial abilities}

In this section, children are classified into several types using Ward's method of cluster analysis, based on the results for the four basic English skills on the first test. The deviation value of the test scores for each of the four elements is analysed to clarify the relations among them, since the four abilities' scores do not have the same scale on the test. The deviation value of child $i$ for element $j$, $d_{i, j}$, was defined by equation (1), where $x_{i, j}$ is the score of child $i$ in English element $j, \overline{x_{j}}$ is the average score for element $j$, and $s_{j}$ is the standard deviation of the score for element $j$.

$$
d_{i, j}=10\left(x_{i, j}-\overline{x_{j}}\right) / s_{j}+50
$$

The average of the deviation values and the size of each cluster, in the process of determining the structure, are presented in Table 13 and Table 14, respectively.

The cluster 1 divided on the case of the 2 clusters divided into the cluster 1 and 2 on the case of 3 clusters. After the division, the differences in average deviation value between clusters 1 and 2 were found to be 12.56 for speaking and 7.66 in total. The cluster 2 divided on the case of the 3 clusters divided into the cluster 2 and 4 on the case of 4 clusters. After the division, the differences in average deviation value between clusters 2 and 4 were found to be 10.59 for speaking, 
but not for the total scores. The cluster 3 divided on the case of the 4 clusters divided into the cluster 3 and 4 on the case of 5 clusters. After the division, the differences in average deviation value between clusters 3 and 4 were found to be 11.44 for speaking; however, the size of cluster 5 decreased to 9 , which is too small to further analyse the structure of English skills. The children were then classified into four types.

Table 13: Average of Deviation Values for Each Classification

\begin{tabular}{|c|c|c|c|c|c|}
\hline \multirow[t]{2}{*}{ Cluster } & \multicolumn{4}{|c|}{ English element ${ }^{a}$} & \multirow[t]{2}{*}{ Total } \\
\hline & $\mathrm{L}$ & $\mathrm{R}$ & W & S & \\
\hline 1 & 43.64 & 42.38 & 42.59 & 45.39 & 42.29 \\
\hline 2 & 58.32 & 59.38 & 59.69 & 56.02 & 60.08 \\
\hline 1 & 48.21 & 47.76 & 44.50 & 54.01 & 47.55 \\
\hline 2 & 41.55 & 40.57 & 41.71 & 41.45 & 39.89 \\
\hline 3 & 58.32 & 59.38 & 59.69 & 56.02 & 60.08 \\
\hline 1 & 48.21 & 47.76 & 44.50 & 54.01 & 47.55 \\
\hline 2 & 41.08 & 37.06 & 39.27 & 45.99 & 38.66 \\
\hline 3 & 58.32 & 59.38 & 59.69 & 56.02 & 60.08 \\
\hline 4 & 42.17 & 45.27 & 44.97 & 35.40 & 41.53 \\
\hline 1 & 48.21 & 47.76 & 44.50 & 54.01 & 47.55 \\
\hline 2 & 41.08 & 37.06 & 39.27 & 45.99 & 38.66 \\
\hline 3 & 56.94 & 58.48 & 58.44 & 58.66 & 59.52 \\
\hline 4 & 62.91 & 62.38 & 63.86 & 47.22 & 61.59 \\
\hline 5 & 42.17 & 45.27 & 44.97 & 35.40 & 41.53 \\
\hline \multicolumn{6}{|c|}{ L = Listening, $\mathrm{R}=$ Reading, $\mathrm{W}=$ Writing, $\mathrm{S}=$ Speakin } \\
\hline \multicolumn{6}{|c|}{ Table 14: Distribution of Samples in Clusters } \\
\hline $\begin{array}{c}\text { Clust } \\
\text { er }\end{array}$ & 1 st & 2nd & 3rd & 4 th & 5th \\
\hline 2 & 51 & 39 & & & \\
\hline 3 & 16 & 35 & 39 & & \\
\hline 4 & 16 & 20 & 39 & 15 & \\
\hline 5 & 16 & 20 & 30 & 9 & 15 \\
\hline
\end{tabular}

The characteristics for English learning of each type were interpreted based on Table 13. Children of type 1 are characterized by strength in speaking, weakness in writing, and the middle level overall. Children of type 2 are characterized by relative strength in speaking, significant weakness in reading, and lower level overall. Children of type 3 are characterized by strength in all abilities, relative weakness speaking, and highest overall level. Children of type 4 are characterized by weakness in speaking and lower level overall.

Table 15: Characteristics of Each Type

\begin{tabular}{clc}
\hline \hline Type & \multicolumn{1}{c}{ Characteristics } & Size \\
\hline 1 & $\begin{array}{l}\text { Middle level, good at speaking, } \\
\text { not so good at writing }\end{array}$ & 16 \\
2 & $\begin{array}{l}\text { Lower level, somewhat good at } \\
\text { speaking, and not good at }\end{array}$ & 20 \\
\hline \hline
\end{tabular}




\begin{tabular}{clc}
\hline \hline 3 & $\begin{array}{l}\text { reading } \\
\text { Higher level, not as good at } \\
\text { speaking }\end{array}$ & 39 \\
4 & $\begin{array}{l}\text { Lower level, not good at } \\
\text { speaking }\end{array}$ & 15 \\
\hline
\end{tabular}

\section{Analysis of English ability structures}

The structure of students' English abilities at the start of this research were obtained using structural equation modelling based on the deviation values of four elements for each type. Because Shukutoku Elementary School provides English classes focusing on listening and reading at lower grades, models with a path from listening or reading to other skills are assumed to be valid. Similarly, models with a path from speaking to listening or from writing to reading, for instance, were rejected in advance. All possible models were then constructed, including differences in path direction of paths, based on the above assumption; the models with the highest AGFI on the four types were accepted respectively.

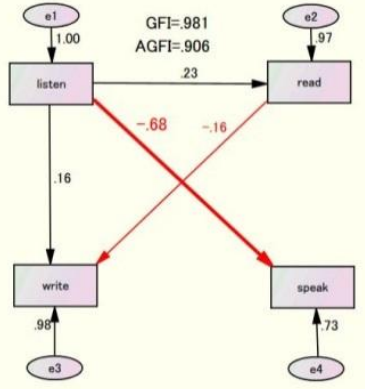

(a) Type 1

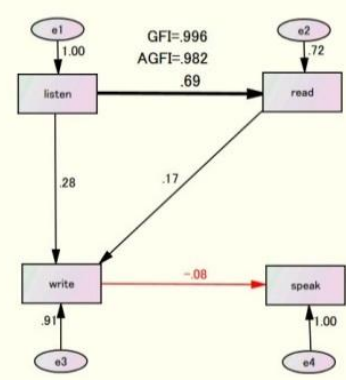

(c) Type 3

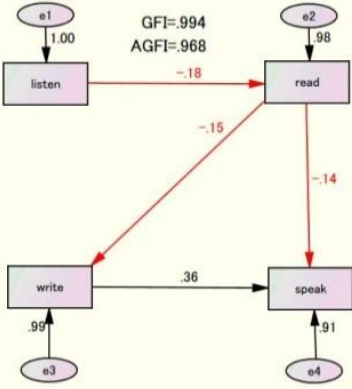

(b) Type 2

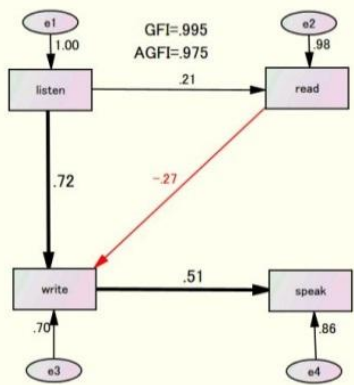

(d) Type 4

Figure 3: English ability structures at the start of this research

In type 1, strong negative relation was found on the path from listening to speaking. Weak positive relation was found on two paths from listening to reading and writing. However, because the children of type 1 are characterized by their strengths of speaking, their speaking abilities are considered to be cultivated independently, and the unlinked structure shows their shallow development in English. Writing is not linked from listening strongly, and the weakest skill. After the first test, then, the children are expected to improve their overall English skills by studying with focus on listening and writing. 
In type 2, negative relation was found on the paths from listening to reading and from reading to writing and speaking, and only one positive relation was obtained, on the path from writing to speaking. Because the negative relations are not strong, in the type 2, the children's abilities are considered to be cultivated independently, except in the case of the positive relation from writing to speaking. After the first test, then, the children are expected to improve their overall English skills by studying with focus on listening, reading and writing.

In type 3, positive relations were found on the paths from reading to writing, listening to writing, and especially listening to reading. A very weak negative relation was found on the path from writing to speaking. Because the children of type 3 are characterized by the highest level, overall they are believed to study English by linking the abilities of listening, reading and writing. Moreover, since the children of type 3 did not show a strong relation between speaking and the other skills, speaking abilities are assumed to be independent. After the first test, then, the children are expected to improve their overall English skills by studying with focus on listening and speaking.

In type 4, positive relations were found on the paths from listening to reading and especially listening to writing. A negative relation was found on the path from reading to writing, and a strong positive relation was found on the path from writing to speaking. With indirect effect, the speaking ability is considered to have strong relationships with the other abilities. Although the children of type 4 are not so good at any of the four English skills, they have presumably learned with links among the skills. After the first test, then, the children are expected to improve their overall English skills by studying with focus on listening and reading.

The hypotheses about effective focus on certain English skills were constructed by those observations, as shown in Table 16.

Table 16: Assumed Effective Focus

\begin{tabular}{cl}
\hline \hline Type & \multicolumn{1}{c}{$\begin{array}{c}\text { Effective English elements for each } \\
\text { type }\end{array}$} \\
\hline 1 & Listening and writing \\
2 & Listening, reading and writing \\
3 & Listening and speaking \\
4 & Listening and reading \\
\hline \hline
\end{tabular}

\section{Analysis of important variables of English learning}

In this section, regression binary tree analysis is used to analyse the learning features of the children who improved in the experiment, where degree of improvement is set as the objective variable and the explanatory variables are those shown in Tables 10 to 12. A regression tree analysis for suggesting meaningful features of learning strategy was used by Matsukawa et al. (2007).

In this research, however, since only primary school grade 2 was targeted, the sample size was not large enough to detect the features of small groups like type 
2 or type 4 . Therefore, children were separated into the English superior group (type 3: $n=39$ ) and the English inferior group (others: $n=51$ ) and analysed respectively. For the latter group, the distribution of children on each terminal node on a regression tree was attempted to investigate the useful variables for characterizing each type; however, clear differences between three types could not be seen.

The standardized value of difference between the two test scores before and after use of the Speaking-pen was set as the objective variable, and the features of children who improved were presented as explanatory variables on the tree structures. The maximum depth of tree was set to five, and a node was separated when the size of a node was greater than five. The trees were obtained with two different variable sets - the variables of interest listed in Table 10, and all the variables listed Tables 10, 11 and 12-in order to evaluate the effectiveness of analysing the learning process with the variables of interest.

\section{Analysis of the English superior group (Typ3: $n=39$ )}

The features of children who showed improvement in overall ability appeared on one tree with the variables of interest, as shown in Figure 4 (a). Overall, the children who scored highly for THINK1 (Learning content related to sentence structure, Value interests) tended to show improvement. Of these, children who scored highly for LISTEN (Experience-based interest in listening, Emotional interests) in particular tended to show improvement. Conversely, for children with a lesser score for LISTEN, some of those who presented even a low score for THINK2 (Learning all content about a story in sequence) still showed improvement.

The features of children showing improvement in overall ability appeared on a second tree with all variables, as shown in Figure. 4 (b). Overall, the THINK1 variable again appeared on the top node of the tree, as in the tree showing only variables of interest. LISTEN was also detected as a feature. In the English superior group (type 3), therefore, the Value interests, which appear on the top node of the tree, are primarily more significant than Emotional interests or variables of self-regulated learning.

The features of children who showed improvement in listening ability appeared on one tree with the variables of interest, as shown in Figure. 5 (a). Overall, children who scored highly for READ (Experience-based interest in reading, Emotional interests) tended to show improvement.

The features of children showing improvement in listening ability appeared on a second tree with all variables, as shown in Figure 5 (b). Overall, READ appeared on the top branch of the tree. The variables of Emotional interests were also abstracted on the top branch of the regression trees for listening improvement. 


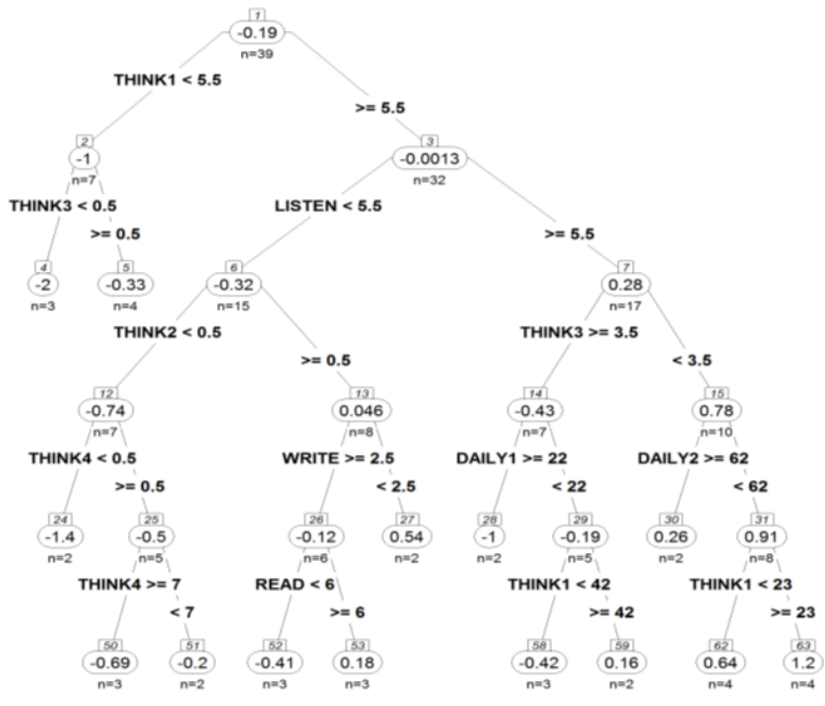

(a) Variables of interest

Figure 4: Features of children showing improvement in total English ability (the

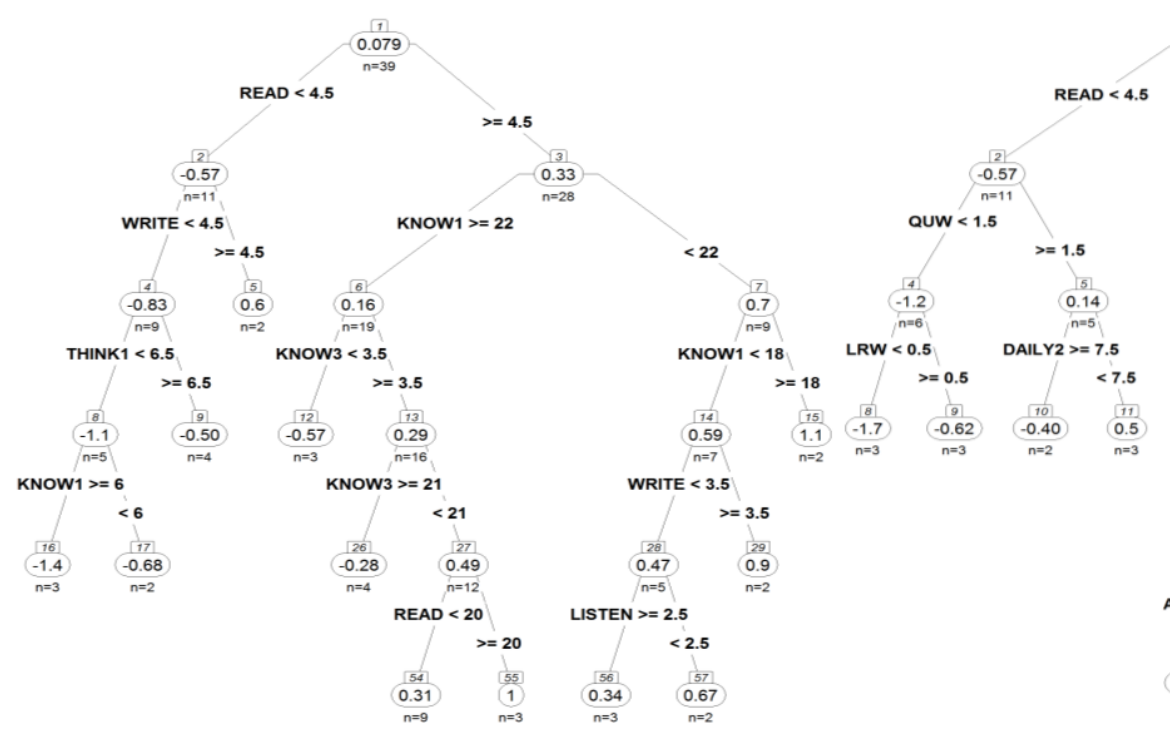

(a) Variables of interest

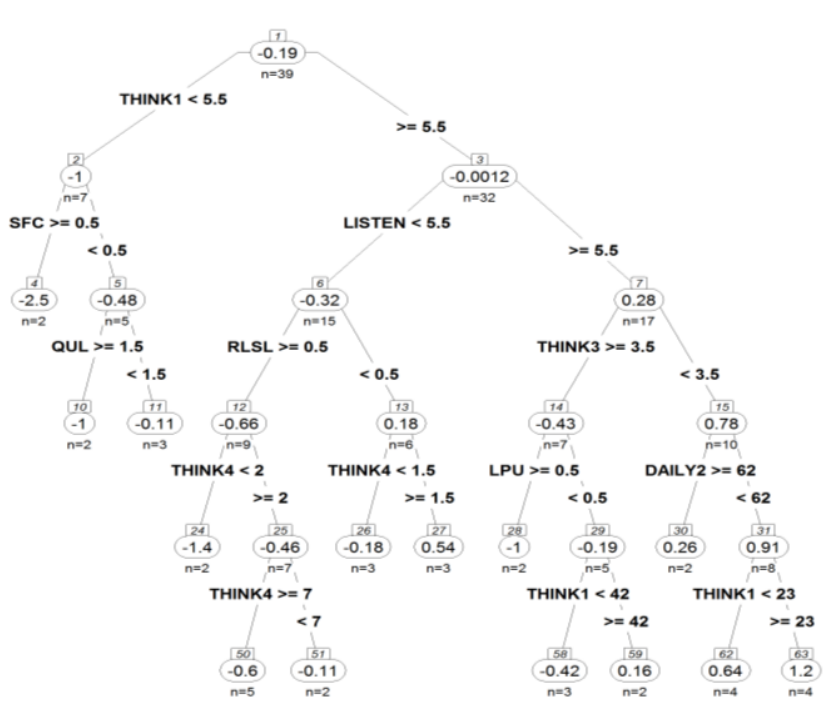

(b) All variables English Superior Group)

Figure 5: Features of children showing improvement in listening ability (the English Superior Group) 

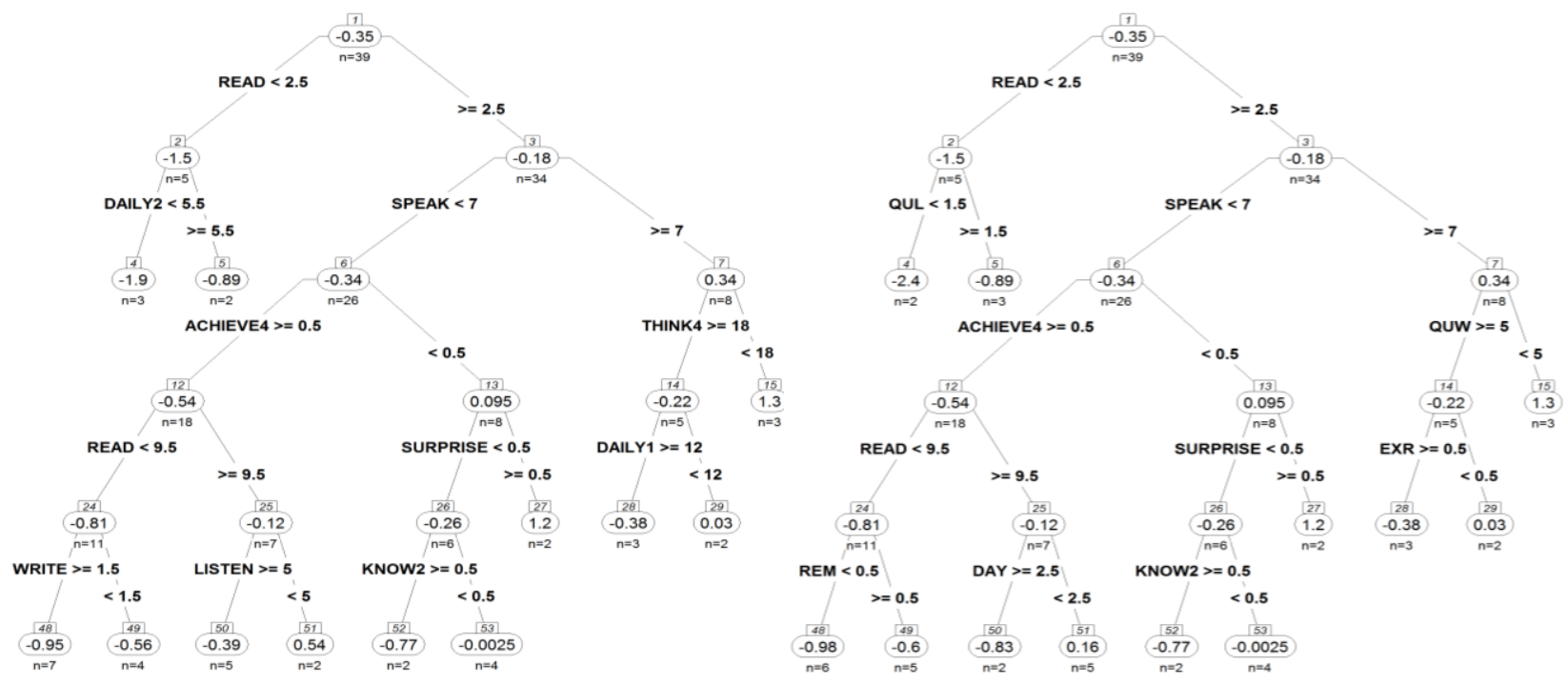

(a) Variables of interest

(b) All variables

Figure 6: Features of children showing improvement in reading ability (the English Superior Group)

The features of children who showed improvement in reading ability appeared on one tree with the variables of interest, as shown in Figure 6 (a). Overall, the children who scored highly for READ tended to show improvement. Among these, children with high scores for SPEAK (Experience-based interest in speaking, Emotional interest) in particular tended to show improvement.

The features of children showing improvement in reading ability also appeared on a tree with all variables, as shown in Figure. 6 (b). Overall, READ again appeared on the top branching of the tree. SPEAK was also detected as a feature. The variables of interest were also abstracted on the top branching of the regression trees of reading improvement, however, as the Emotional interests.

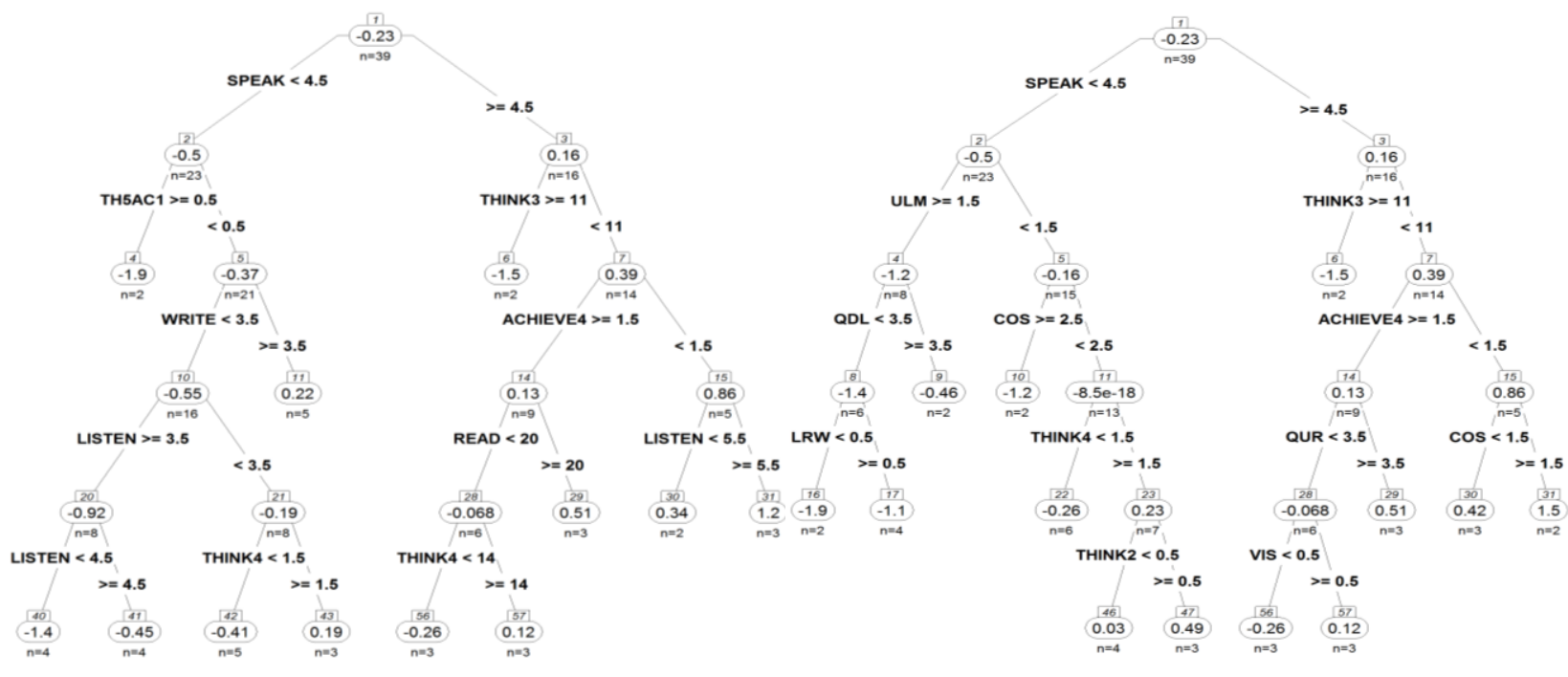

(a) Variables of interest

(b) All variables

Figure 7: Features of children showing improvement in writing ability (the English Superior Group) 


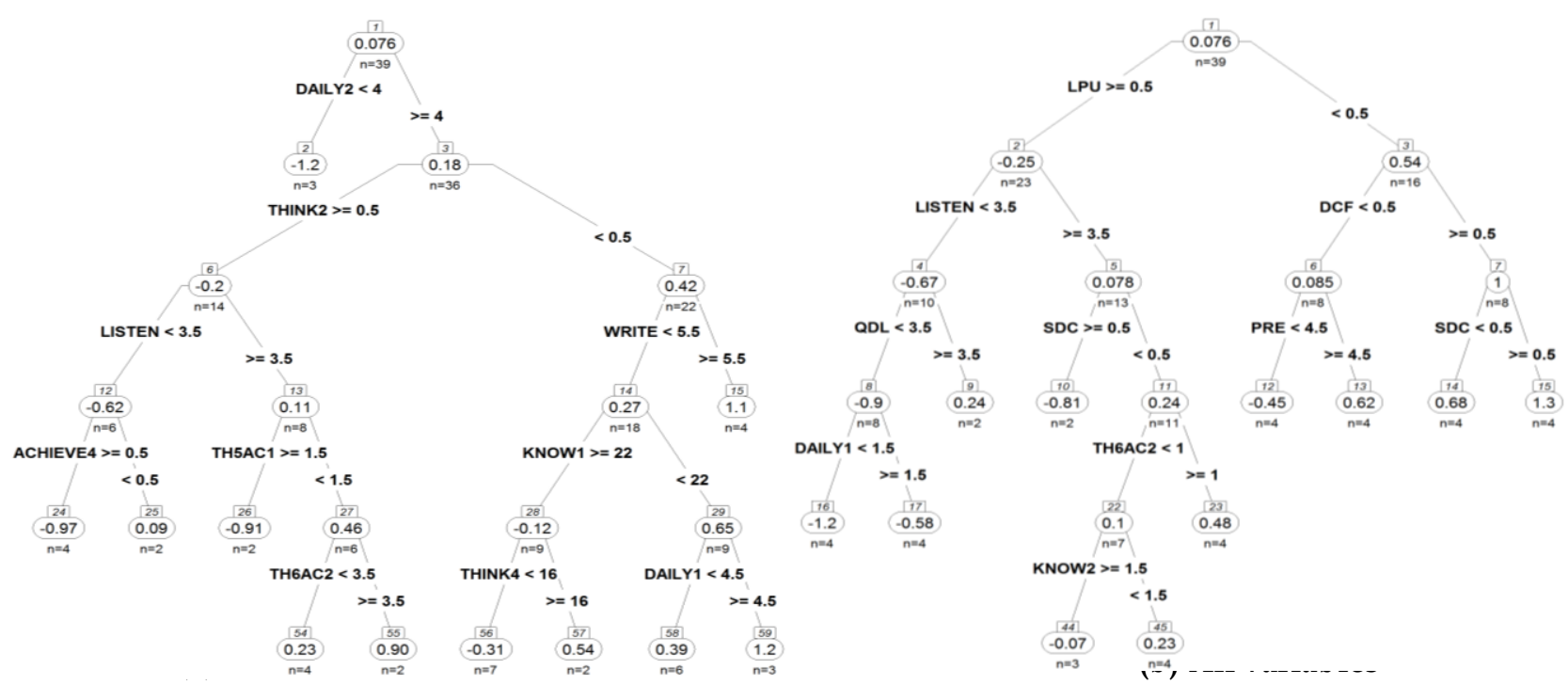

Figure 8: Features of children showing improvement in speaking ability (the English Superior Group)

The features of children showing improvement in writing ability appeared on one tree with the variables of interest, as shown in Figure. 7 (a). Overall, the children with high scores for SPEAK tended to show improvement.

The features of children showing improvement in writing ability appeared also on a tree with all variables, as shown in Figure. 7 (b). Overall, SPEAK again appeared on the top branching of the tree. The variables of interest were also abstracted on the top branching of the regression trees for writing improvement as Emotional interests.

The features of children showing improvement in speaking ability appeared on a tree with the variables of interest, as shown in Figure. 8 (a). Overall, the children with high scores for DAILY2 (Learning sentences related to daily life, Value interests) tended to show improvement.

\section{Analysis of the English inferior group (Types 1, 2 and 4: $n=51$ )}

The features of children who showed improvement in overall ability appeared on a tree with the variables of interest, as shown in Figure. 9 (a). Overall, the children with high scores for ACHIEVE4 (Learning questions repeatedly after the correct answer was obtained, Emotional interests) tended to show improvement. Of these, children with high scores for THINK4 (Solving difficult questions correctly, Value interests) scores tended to improve, and in particular those with high scores for TH6AC2 (Learning sentences by skipping through more than two parts).

The features of children showing improvement in total ability also appeared on a tree with all variables, as shown in Figure. 9 (b). Overall, ACHIEVE4 again appeared on the top branching of the tree. Among children with high ACHIEVE4 scores, those who also had high scores for DAY (Study days, 
learning strategy, self-regulated learning) tended to show improvement, and in particular those with high LISTEN scores.

The features of children showing improvement in listening ability appeared on a tree with the variables of interest, as shown in Figure. 10 (a). Overall, the children with high READ scores tended to show improvement.

The features of children showing improvement in listening ability also appeared on a tree with all variables, as shown in Figure. 10 (b). Overall, the children who scored highly scored for QUW (Quantity of writing learning) tended to show improvement.

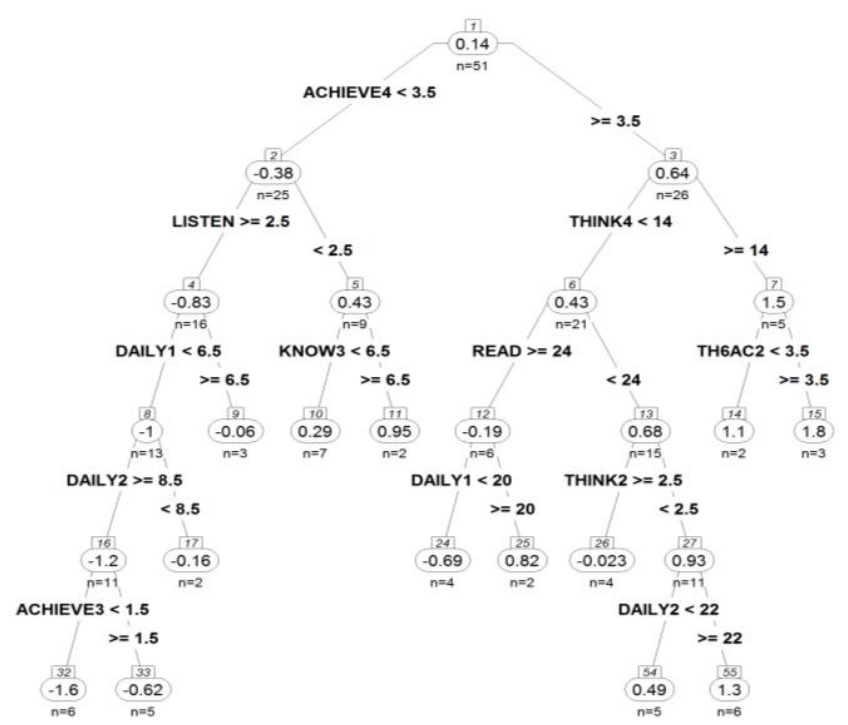

(a) Variables of interest

Figure 9: Features of children showing improvement in total English ability (the English Inferior Group)

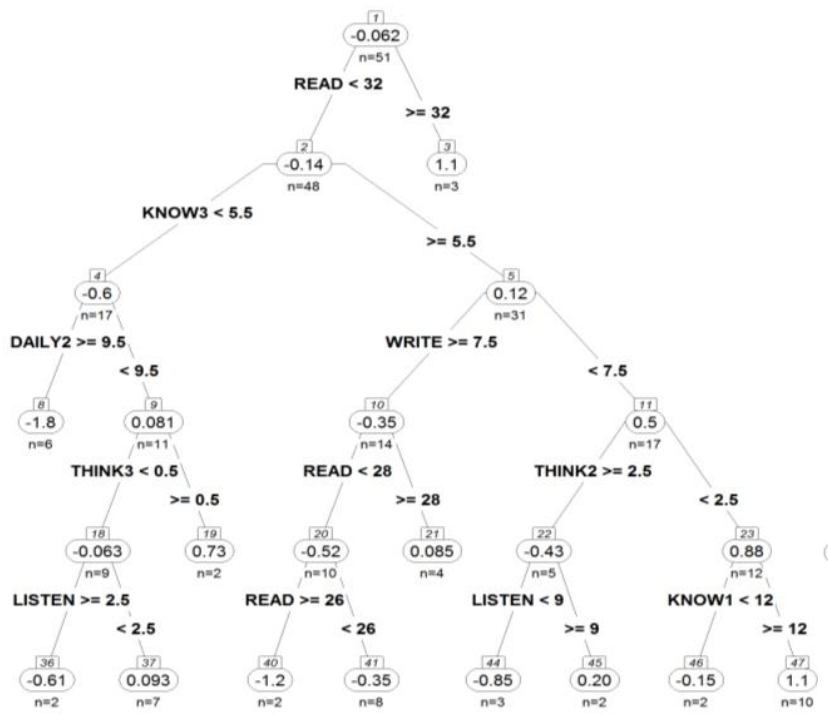

(a) Variables of interest Figure 10: Features of children showing improvement in listening ability (the English Inferior Group) 


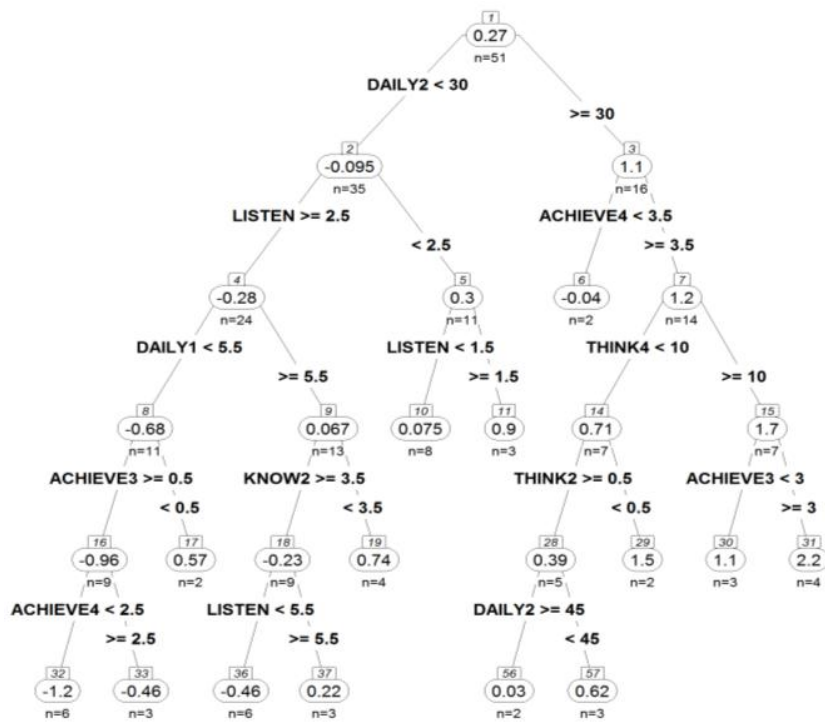

(a) Variables of interest

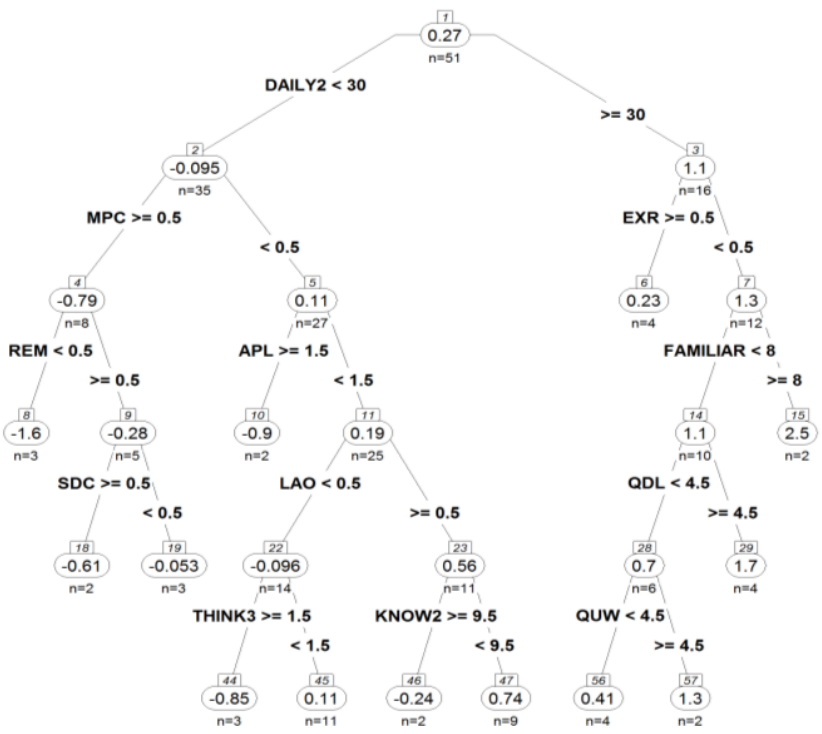

(b) All variables

Figure 11: Features of children showing improvement in reading ability (the English Inferior Group)

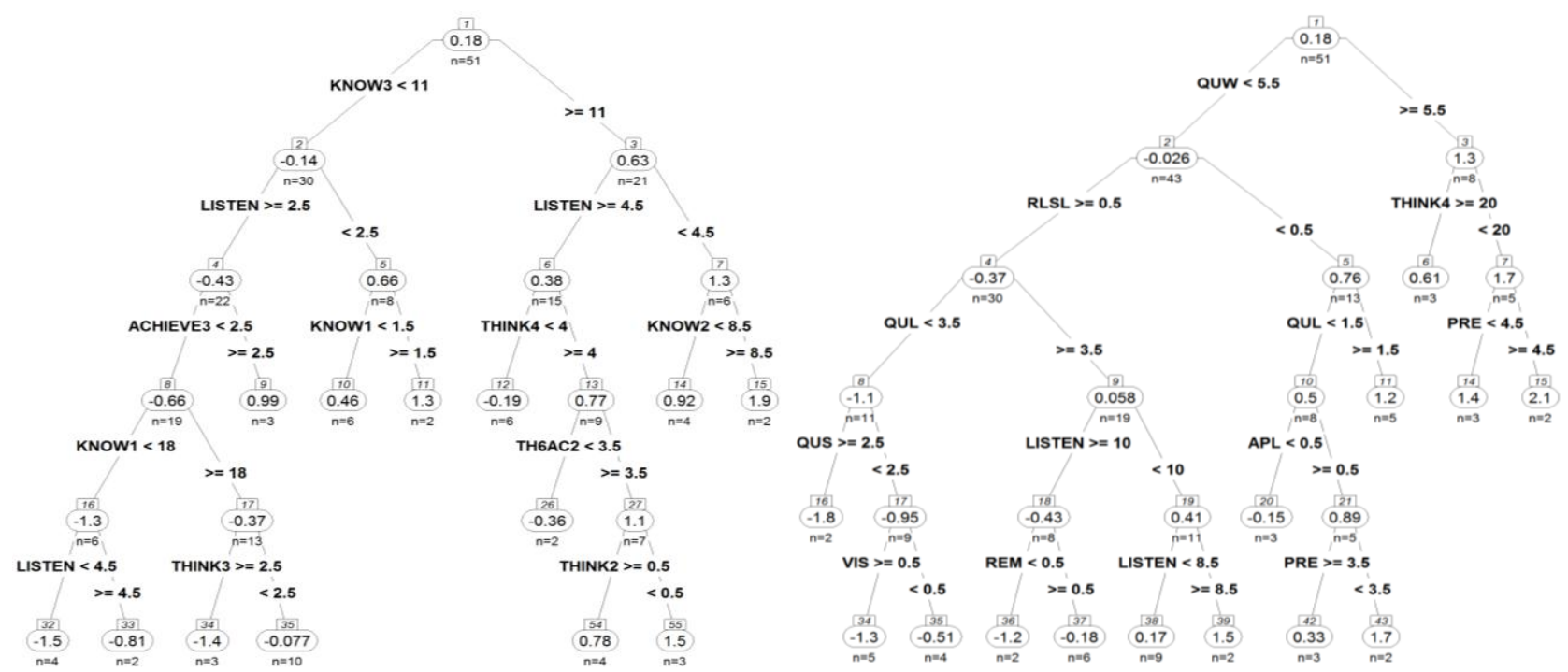

(a) Variables of interest

(b) All variables

Figure 12: Features of children showing improvement in writing ability (the English Inferior Group) 


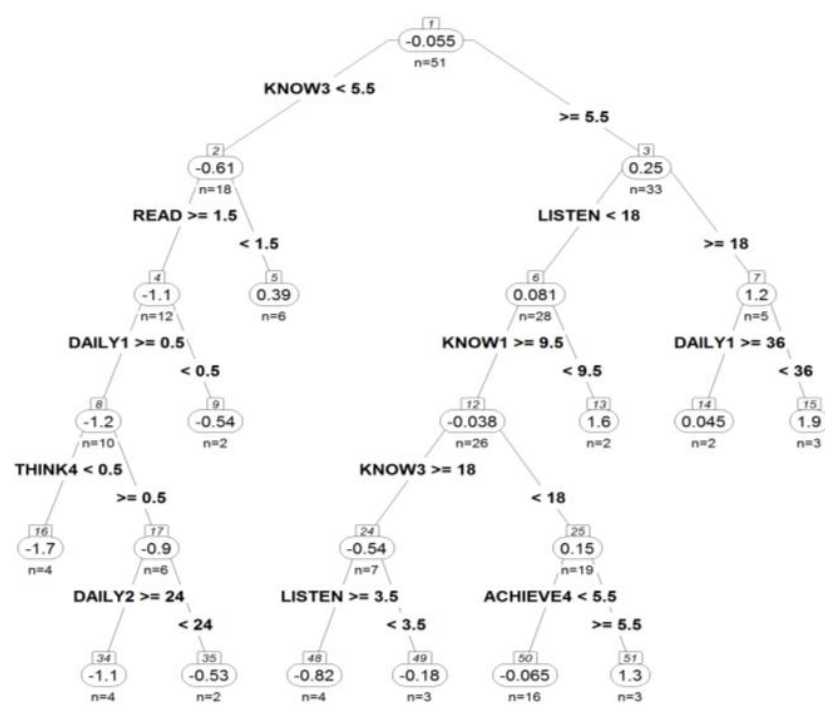

(a) Variables of interest

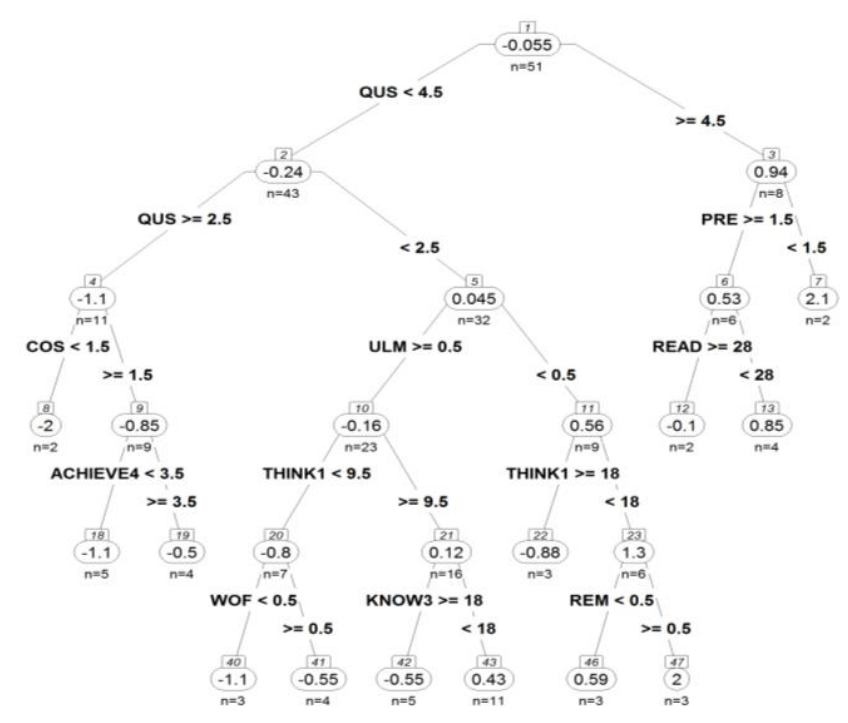

(b) All variables

Figure 13: Features of children showing improvement in speaking ability (the English Inferior Group)

The features of children showing improvement in reading ability appeared on a tree with the variables of interest, as shown in Figure. 11 (a). Overall, children who scored highly for DAILY2 (Learning sentences related to daily life, Value interests) tended to show improvement. Of those, children with high scores for ACHIEVE4 (Learning questions repeatedly after the correct answer was obtained, Emotional interests) tended to improve, and in particular those with high scores for THINK4 (Solving difficult questions correctly).

The features of children showing improvement in reading ability also appeared on the tree with all variables, as shown in Figure. 11 (b). Overall, DAILY2 again appeared on the top branching of the tree.

The features of children showing improvement in writing ability appeared on a tree with the variables of interest, as shown in Figure. 12 (a). Overall, the children who scored highly scored for KNOW3 (Learning all items in one part, Value interests) tended to show improvement.

The features of children showing improvement in writing ability also appeared on the tree with all variables, as shown in Figure. 12 (b). Overall, the children with high scores for QUW (Quantity of writing learning) tended to show improvement.

The features of children showing improvement in speaking ability appeared on a tree with the variables of interest, as shown in Figure. 13 (a). Overall, the children with high scores for KNOW3 (Learning all items in one part, Value interests) tended to show improvement. Of these, children with high LISTEN scores tended to improve.

The features of children showing improvement in speaking ability also appeared on a tree with all variables, as shown in Figure. 13 (b). Overall, the children 
scored highly for QUS (Quantity of speaking learning) tended to show improvement.

The series of improved children's features, abstracted as variables, are listed in Table 17.

Table 17: Features of Children Showing Improvement

\begin{tabular}{|c|c|c|c|c|c|}
\hline & \multirow[b]{2}{*}{ Element } & \multicolumn{4}{|c|}{ Variables } \\
\hline & & English education & $\begin{array}{l}\text { Self-regulated } \\
\text { learning }\end{array}$ & Value interests & Emotional interests \\
\hline English & $\mathrm{L}$ & & & & READ \\
\hline Superior & $\mathrm{R}$ & & & & READ, SPEAK \\
\hline Group & W & & & & SPEAK \\
\hline \multirow{2}{*}{ (Type 3) } & $S$ & & & DAILY2 & \\
\hline & $\mathrm{T}$ & & & THINK1, THINK2 & LISTEN \\
\hline English & $\mathrm{L}$ & QUW & & KNOW3 & READ \\
\hline Inferior & $\mathrm{R}$ & & & DAILY2, THINK4 & ACHIEVE3, \\
\hline \multirow{3}{*}{$\begin{array}{l}\text { (Types 1,2 } \\
\text { and 4) }\end{array}$} & W & OUW & & KNOW3 & ACHIEVE4 \\
\hline & $\mathrm{S}$ & QUS & & KNOW3 & LISTEN \\
\hline & $\mathrm{T}$ & & DCF, DAY & THINK4 & $\begin{array}{c}\text { THINK6, ACHIEVE4, } \\
\text { LISTEN }\end{array}$ \\
\hline
\end{tabular}

\section{Discussion}

In the English Superior Group (type 3), the specific features of children who showed improvement, as listed in Table 17, are the Value interests of DAILY2 (Learning sentences related to daily life), THINK1 (Learning content related to sentence structure) and THINK2 (Learning all content about a story in sequence), and the Emotional interests of experience-based interest in listening, reading and speaking. These children, therefore, had to study various parts of the textbook to improve their English skills. The learning method assumed to be most effective for children of type 3 was focus on listening and speaking; the listening study feature, indicated by LISTEN, was actually abstracted on the tree of children who improved overall English skill, as shown in Table 18. Emotional interests commonly appeared in the top layer for listening, reading and writing skills; they did not for the speaking skill. Assuming a specialty in speaking, the effective method for improving this skill is different than that for the others.

Table 18: Assumed and Actual Effective Focus for Type 3 Children

\begin{tabular}{|c|c|c|c|c|c|}
\hline & \multicolumn{4}{|c|}{ English element } & \multirow[t]{2}{*}{ Overall } \\
\hline & $\mathrm{L}$ & $\mathrm{R}$ & W & S & \\
\hline $\mathrm{L}$ & & & & & YES \\
\hline $\mathrm{R}$ & YES & YES & & & \\
\hline $\begin{array}{c}W \\
S\end{array}$ & & YES & YES & & \\
\hline
\end{tabular}

Highlighted rows indicate hypothesized effective focus. 
For the children of the English Inferior Group (types 1, 2 and 4), the common features obtained by the trees were ACHIEVE4 (Studying questions repeatedly after the correct answer was obtained, Emotional interests), KNOW3 (Learning all items in one part, Value interests) and THINK4 (Solving difficult questions correctly, Value interests). Thus, children of types 1, 2 or 4 would improve their overall English skill by focusing on listening, which also affected speaking skill. The feature of writing study is confirmed by the appearance of the QUW (Quantity of writing learning) variable, abstracted in the demonstrated improvements of both listening and writing skill. For reading skill improvement, however, no other English skills' features had an effect, as shown in Table 17. As a common suggestion for the entire English Inferior Group (types 1, 2 and 4), the strategy that best improves overall total ability through practice with listening should be applied. The more specific assumed effective learning methods for children of types 1, 2 and 4 are listed in Tables 19 to 21 . However, because only the common features for the group were detected by the regression trees, the listening study feature indicated by LISTEN was concluded to affect overall improvement by combining the hypotheses for each type and the results in Table 17. Thus, although the hypotheses were found valid, a strategy for improving reading skill was also found to be necessary. Additionally, for type 4, a strategy for improving writing skill is found to be necessary.

Table 19: Assumed and Actual Effective Focus for Type 1 Children

\begin{tabular}{|c|c|c|c|c|c|}
\hline & \multicolumn{4}{|c|}{ English element } & \multirow[t]{2}{*}{ Overall } \\
\hline & $\mathrm{L}$ & $\mathrm{R}$ & $\mathrm{W}$ & $S$ & \\
\hline $\mathrm{L}$ & & & & YES & YES \\
\hline $\mathrm{R}$ & YES & & & & \\
\hline W & YES & & YES & & \\
\hline$S$ & & & & YES & \\
\hline
\end{tabular}

Highlighted rows indicate hypothesized effective focus.

Table 20: Assumed and Actual Effective Focus for Type 2 Children

\begin{tabular}{|c|c|c|c|c|c|}
\hline & \multicolumn{4}{|c|}{ English element } & \multirow[t]{2}{*}{ Overall } \\
\hline & $\mathrm{L}$ & $\mathrm{R}$ & $W$ & $S$ & \\
\hline L & & & & YES & YES \\
\hline $\mathrm{R}$ & YES & & & & \\
\hline W & YES & & YES & & \\
\hline$S$ & & & & YES & \\
\hline
\end{tabular}

Highlighted rows indicate hypothesized effective focus.

Table 21: Assumed and Actual Effective Focus for Type 4 Children

\begin{tabular}{|c|c|c|c|c|c|}
\hline & \multicolumn{4}{|c|}{ English element } & \multirow[t]{2}{*}{ Overall } \\
\hline & $\mathrm{L}$ & $\mathrm{R}$ & W & $S$ & \\
\hline $\mathrm{L}$ & & & & YES & YES \\
\hline $\mathrm{R}$ & YES & & & & \\
\hline W & YES & & YES & & \\
\hline$S$ & & & & YES & \\
\hline
\end{tabular}

Highlighted rows indicate hypothesized effective focus. 
Significant difference was confirmed between the features of children showing improvement in the English Superior Group and the English Inferior Group. For overall abilities, Value interests for the English Superior Group and Emotional interests for the English Inferior Group were selected as the variables that determine the first branching of regression trees. However, for the four main English skills, the reverse tendency was found. For the English Superior Group, Emotional interests such as experience-based interest were selected as the variables that determine the first branching of regression trees. On the contrary, for the English Inferior Group), Value interests were selected for the three English skills other than listening. Another difference was found in the variables of self-regulated learning; DCF (Desire for communication with foreigners) and DAY (Study days) were selected only in the English Inferior Group.

Though various patterns of children's interests were observed on regression tree, we were not able to divide children into more than two groups because sample size was not large enough. For further research, larger samples are required in order to discuss learners' interests based on more detailed typed children.

\section{Conclusion}

In this research, variables of children's interests in English learning were proposed through analysis of learning process log data obtained using Speaking-pens. The children were classified into four types based on their initial abilities, and the English skill structures of each type were analysed. Subsequently, the utility of the proposed interest variables, in terms of explaining improvement of English skills, was examined by comparing two regression trees analysed using different sets of variables.

For the English Superior Group (type 3), it was found that children who have Value interests based on daily life and vitalizing thinking, like DAILY1 (Learning words related to daily life), DAILY2 (Learning sentences related to daily life), THINK1 (Learning content related to sentence structure) and THINK2 (Learning all content about a story in sequence), and study English with interest based on experience of the listening, reading and speaking skills, must advance through practice in each English skill in order to further improve their English abilities. Focus on listening and speaking skills was hypothesized to improve the overall English abilities of type 3, and therefore, interests based on experience of listening and speaking were considered to be good factors for improvement of overall English ability. For the specific English skills of listening, reading and writing, Emotional interests appeared on the top branching of regression trees; they did not on the tree for the speaking skill. This indicated that special factors affect improvement of the speaking skill.

For the English Inferior Group (types 1, 2 and 4), it was found that study of listening would affect speaking skills and overall English ability. Emotional interests based on achievement, such as ACHIEVE3 (Continuing to solve questions with wrong answers until the correct answer was obtained) and ACHIEVE4 (Studying questions repeatedly after the correct answer was obtained), and Value interests based on acquiring knowledge and vitalizing 
thinking, such as KNOW3 (Learning all items in one part) and THINK4 (Solving difficult questions correctly) were found to factor in their learning. Since effect on reading was not found in the trees as a feature of any other skill, a strategy that improves reading ability specifically should be developed. The hypotheses suggested focus on listening and writing to improve the overall English abilities of type 1; focus on listening, reading and writing for type 2; and focus on listening and reading for type 4 . Based on the results obtained, the hypothesized learning method suggestions were considered valid.

Significant differences were confirmed between the English Superior Group and the English Inferior Group (types 1, 2 and 4) by the appearance of different types of interests.

\section{References}

Ainley, M., and Ainley, J. (2011). Student engagement with science in early adolescence: The contribution of enjoyment to students' continuing interest in learning about science. Contemporary Educational Psychology, 36, 4-12. https://doi.org/10.1016/j.cedpsych.2010.08.001

Ainley, M., Hidi, S., and Berndorff, D. (2002). Interest, learning, and the psychological processes that mediate their relationship. Journal of Educational Psychology, 94, 541-561. http://dx.doi.org/10.1037/0022-0663.94.3.545

Brown, A.L. and Campione, J.C. (1981). Inducing Flexible Thinking: The problem of access. In Friendman, M.P. Das, .P. and O'Connor, N.(eds.), Intelligence and Learning. Plenum Press, pp.515-529. https://doi.org/10.1007/978-1-4684-1083-9_49

Flavell, J.H. (1976). Metacognitive Aspects of Problem Solving. In Resnick, L. B.(ed), The Nature of Intelligence. IEA, 231-235.

Hidi, S. (1990). Interest and its contribution as a mental resource for learning. Review of Educational Research, 60(4), 549-571.

Liu, T.Y., and Chu, Y.L. (2010). Using ubiquitous games in an English listening and speaking course: Impact on learning outcomes and motivation. Computers $\mathcal{E}$ Education, 55, 630-643. https://doi.org/10.1016/j.compedu.2010.02.023

Matsukawa, H., Kitamura, S., Nagamori, Y., Hisamatsu, S., Yamauchi, Y., Nakano, M., ... Miyashita, N. (2007). Development of a feedback system of learning strategy to students utilizing data mining technology. Japan Society for Educational Technology, 31(3), 307-316.

Mavilidi, MF., Okely, A.D., Chandler, P, Cliff, D.P. and Paas, F. (2015). Effects of Integrated Physical Exercises and Gestures on Preschool Children's Foreign Language Vocabulary Learning, Educational Psychology Review, 27(3), 413-426. https://doi.org/10.1007/s10648-015-9337-z

Ministry of Education, Culture, Sports, Science and Technology. (2009). The current course of study. Retrieved from http://www.mext.go.jp/a_menu/shotou/new-cs/youryou/syo/gai.htm

Ministry of Education, Culture, Sports, Science and Technology. (2013). English Education Reform Plan Corresponding to Globalization. Retrieved from http://www.mext.go.jp/english/topics/_icsFiles/afieldfile/2014/01/23/1343 591_1.pdf

Ministry of Education, Culture, Sports, Science and Technology. (2014, October). Five proposals and specific measures for developing proficiency in English for 
international communication. Retrieved from http://www.mext.go.jp/b_menu/shingi/chousa/shotou/102/houkoku/attach /1352464.htm

Nunan, D. (2003). The impact of English as a global language on educational policies and practices in the Asia-Pacific region. TESOL Quarterly, 37(4), 589-613.

Pintrich, P.R., and De Groot, E.V.(1990). Motivational and self-regulated learning Components of classroom academic performance, Journal of Educational Psychology, 82(1), 33-40.

Renninger, K. A., Ewen, L., and Lasher, A. K. (2002). Individual interest as context in expository text and mathematical word problems. Learning and Instruction, 12, 467-491. https://doi.org/10.1016/S0959-4752(01)00012-3

Schiefele, U. (1996). Topic interest, text representation, and quality of experience. Contemporary Educational Psychology, 21, 3-18.

https://doi.org/10.1080/00461520.1991.9653136

Tanaka, E. (2015). Classification of students' interests in science and relation of interests to use of deep-processing learning strategies and spontaneous learning behavior. Japanese Journal of Educational Psychology, 63, 23-36. https://doi.org/10.5926/jjep.63.23

Tono, Y. (2012, August 28). The 1st constant meeting of the learning goals set in the form of the "Can-Do list" in the foreign language education. Retrieved from http://www.mext.go.jp/b_menu/shingi/chousa/shotou/092/shiryo/_icsFile s/afieldfile/2012/09/24/1325972_2_1.pdf

Tsubaki, M., Gonda, S., Kato, N., and Maeda, Y. (2015). A study on modeling and verification for improvement of English abilities of elementary school students based on the analysis of log data of learning process using the sound pen. Educational Information Research, 31(1), 43-54. https://doi.org/10.20694/jjsei.31.1_43

Zimmerman, B. J. (1986). Development of self-regulated learning: Which are the key subprocesses?, Contemporary Educational Psychology, 16, 307-313.

Zimmerman, B. J. (1989). Models of self-regulated learning and academic achievement. In B. J. Zimmerman \& D. H. Schunk (Eds.), Self-regulated Learning and Academic Achievement: Theory, Research, and Practice (pp. 1-25). New York: Springer. https://doi.org/10.1007/978-1-4612-3618-4_1

Zimmerman, B. J., and Martinez-Pons, M. (1986). Development of a structured interview for assessing student use of self-regulated learning strategies. American Educational Research Journal, 23(4), 614-628. 